\title{
Investigation of proportionate prevalence of new castle disease in chicken, pigeon and duck at selected veterinary hospitals in Bangladesh and India
}

\begin{abstract}
A prospective study was conducted to evaluate the prevalence of Newcastle Disease (ND) in pigeon, chicken and duck at selected Veterinary Hospital, in Bangladesh and India during December 2015 to May 2016. A total of 245 ND cases were identified by anamnesis, manifesting signs and clinical and physical examination and occasionally postmortem examination. The aim of the study was to estimate proportionate prevalence of ND in pigeon chicken, duck and investigate the distribution of ND according to different factors. Information about species, age sex, and season's time required showing clinical signs, knowledge about ND vaccine were composed by extensive cross-questioning through pre-structured questionnaire over the owners. The proportionate prevalence was found higher in pigeon (58.9\%) irrespective of study placements. The prevalence of ND was highest in summer season (50.6\%) and lowest in rainy season $(10.2 \%)$. Younger birds 20 to $65 \%$ are more susceptible to ND irrespective of age. The proportionate prevalence in male and female was 14.2 to $53.8 \%$ and 16.7 to $60.9 \%$, respectively. Among the body system digestive system was more affected (42.04\%) than the nervous system $(20 \%)$.
\end{abstract}

Volume 4 Issue 2 - 2016

\author{
Tahura Munmun,' Kazi Muhammad Fakhrul \\ Islam,' Shah Jalal,' Tridip Das,' Rakib \\ Tofazzol,' Kamrul Islam, ${ }^{2}$ Rashedul Alam' \\ 'Chittagong Veterinary and Animal Sciences University, \\ Bangladesh \\ Institute of Epidemiology, Disease Control and Research \\ (IEDCR), Bangladesh
}

Correspondence: Tahura Munmun, Chittagong Veterinary and Animal Sciences University, Chittagong, Bangladesh, Tel +88 018 51366860, Email tahura.munmun@gmail.com

Received: August 16, 2016 | Published: November 25, 2016

Keywords: newcastle disease, prevalence, species, anamnesis

Abbreviations: ND, newcastle disease; APMV-1, avian paramyxovirus type 1; ICPI, intracerebral pathogenicity index

\section{Introduction}

Newcastle Disease (ND) is an acute, mild to severe, highly infectious and pathogenic disease of domestic poultry, caged and aviary birds as well as wild birds caused by specified viruses of the Avian Paramyxovirus Type 1 (APMV-1). ${ }^{1,2}$ The disease is acute contagious which is characterized by sudden onset and rapid spread within the flock resulting high morbidity and mortality. Newcastle disease is caused by avian paramyxovirus serotype 1 (APMV1) viruses have been placed in the genus Rubula virus, sub-family Paramyxovirinae, family Paramyxoviridae. ${ }^{3}$ Newcastle disease virus, is a negative-sense single-stranded RNA virus. ND infections have been established in at least 241 species of birds representing 27 of the 50 orders of the class. ${ }^{4}$ The natural hosts of NDV are domestic poultry including chickens, turkeys, ducks, geese, pigeons, quail, pheasants, guinea fowl and ostriches and many species of captive caged birds and wild birds. ${ }^{5}$ In most species of bird the young are more susceptible than the adult. ${ }^{6} \mathrm{~A}$ wide range of avian and non-avian species act as reservoirs of NDV and transmit the disease.

The current OIE definition ${ }^{7}$ is: Newcastle disease is defined as an infection of birds caused by a virus of avian paramyxovirus serotype 1 (APMV-1) that meets one of the following criteria for virulence:

A. The virus has an intracerebral pathogenicity index (ICPI) in day-old chicks (Gallus gallus) of 0.7 or greater or

B. Multiple basic amino acids have been demonstrated in the virus (either directly or by deduction) at the C-terminus of the F2 protein and phenylalanine at residue 117 . Which is the N-terminus of the FI protein. The term "multiple basic amino acids" refers to at least three arginine or lysine residues between residues 113 to 116. Failure to demonstrate the characteristic pattern of amino acid residues as described above would require characterization of the isolated virus by an ICPI test.

Newcastle disease (ND) is a highly contagious viral disease that attacks many species of domestic and wild birds. ${ }^{8}$ Through restriction site mapping and sequence analysis of the fusion gene (F-gene), NDV strains have been divided into eight genotypes. ${ }^{9}$ The strains are also classified into highly virulent (velogenic), intermediate (mesogenic) or avirulent (lentogenic) based on their pathogenicity in chickens. ${ }^{10}$ On this basis NDVs have been placed in 5 pathotypes or groups: ${ }^{10}$

i. Viscerotropic velogenic: Viruses responsible for disease characterized by acute lethal infection, usually with hemorrhagic lesions in the intestines of dead birds.

ii. Neurotropic velogenic: Viruses causing disease characterized by high mortality, which follows respiratory and neurological disease, but in which gut lesions are usually absent.

iii. Mesogenic: Viruses causing clinical signs consisting of respiratory and neurological signs, with low mortality.

iv. Lentogenic: Viruses causing mild infections of the respiratory tract.

v. Asymptomatic enteric: Viruses causing virulent infections in which replication appear to occur primarily in the gut.

ND is reported as the most important viral disease of poultry in the world including developing countries. ${ }^{11}$ In Africa and Asia ND is a major constraint against the development of both industrial and village poultry production. NDV infections of poultry range from latent to rapidly fatal depending upon the pathotype of virus involved. ${ }^{2}$ The 
transmission of NDV occurs through newly introduced birds, selling or giving away sick birds, exposure to fecal and other excretions from infected birds and contact with contaminated feed, water, equipment and clothing. ${ }^{12}$ The routes of NDV is nasal, oral, ocular.

\section{Pathogenesis of newcastle disease is given below}

a. Ingestion/inhalation of infected material-replication take place in the upper respiratory tract-avirulent (lentogenic) virus remains localized there and infection is sub-clinical unless secondary infection occurs. Virulent NDVs (mesogenic and velogenic) replicate outside the respiratory epithelium-bloodstream-target organs.

b. Incubation period of Newcastle Disease Virus is 2-15days (avg. 5-6days).

c. Clinical signs depend on virulence and tropism of the virus, the age of the bird and the immune status of the birds, the route of exposure, the magnitude and duration of the infecting dose, the susceptibility of the host species, and external factors social stress and temperature. ${ }^{13}$

d. In per-acute case: sudden death.

e. VVND: Mortality up to $100 \%$. Restlessness, weakness, depression, edema of the head and wattles, greenish diarrhoea. The appearance of soft-shell or shell-less eggs, followed by complete cessation of egg laying. ${ }^{14}$

f. NVND: Morbidity up to $100 \%$, mortality $50-90 \%$. Sudden severe respiratory distress, muscular tremors, torticollis, paralysis, opisthotonus, drop in egg production.

g. Mesogenic strain: Respiratory disturbances followed nervous signs, with mortality rates reaching $50 \%$ or more. ${ }^{14}$

h. Lentogenic strain: Mild respiratory disturbances, or no signs.

i. Haemorrhagic lesions of the gastrointestinal tract, especially the proventriculus, may vary considerably in size and severity. ${ }^{11}$ Tracheitis, often haemorrhagic. Air-sacculitis, appear cloudy and congested. Thickening of the air sacs with catarrhal or caseous exudates is often observed. ${ }^{10}$

The disease causes high economic losses due to high mortality, morbidity, stress, decreased egg production and hatchability. ${ }^{5}$ No treatment for NDV exists, but the use of prophylactic vaccines and sanitary measures reduces the likelihood of outbreaks. Vaccination has been reported as the only safeguard against endemic ND. ${ }^{15}$ The current vaccination schedule in Bangladesh directed by the Directorate of Livestock Services (DLS) includes administration of a live lentogenic vaccine (BCRDV) of F-strain by intra-ocular instillation to chicks followed by a live mesogenic vaccine (RDV) of M-strain by intramuscular injection at 21 days old chicks which is repeated at every six months interval. The infection still occurs in Bangladesh every year in the form of epidemic and appears to cause up to $40-60 \%$ of the total mortality in poultry population creating one of the major problems in the development of poultry industry in Bangladesh. ${ }^{16}$ Chicks from immunized parents possess high level of maternally derived antibodies (MDA) which protect them against virulent and vaccine viruses. ${ }^{17,18}$ It was reported that MDA are protective ${ }^{18}$ and neutralize vaccine virus if the chicks are vaccinated in the presence of high level of MDA. In order to formulate appropriate vaccination schedule and control measures the serological status of NDV among chickens need to be elucidated.
The present investigation was conducted at three veterinary hospitals for Newcastle Disease clinical study. Upazilla Veterinary Hospital, Hathazari (UVH) and Shahedul Alam Quaderi Teaching Veterinary Hospital (SAQTVH) receive different clinical cases in poultry for treatment purposes. Tamil Nadu Veterinary and Animal Sciences University (TANUVAS) receive clinical cases of poultry. However ND investigation in different animal species was designed with following objectives:

i. To estimate the proportionate prevalence of Newcastle Disease in chicken, pigeon, duck at selected veterinary hospitals in Bangladesh and India.

ii. To investigate factors passively influencing the occurrence of ND.

iii. To describe frequency of clinical symptoms of ND in chicken, duck, pigeon.

\section{Materials and methods}

\section{Study area and duration}

Investigation of clinical Newcastle Disease cases of different poultry were studied during 5 months internship period at three different places which were Upazilla Veterinary Hospital, Hathazari (14 February to 24 March 2016), SAQTVH (21 December 2015 to 8 February 2016), Bangladesh and TANUVAS (15 April to 15 May 2016), India.

\section{Study population}

A total of 631 clinical cases in chicken, pigeon and duck were investigated during the study period. In addition to ND cases other clinical cases in chicken, pigeon and duck were also recorded to be used as denominator to calculate the proportionate prevalence of Newcastle Disease case. Clinical and physical examination was carried out for each individual case. Data recorded for each case using the structured questionnaire included species, age, sex, breed, temperature, season, date of case occurrence, clinical signs, vaccination history, flock size and mortality rate.

\section{Data collection}

Information about ND and its treatment and management were also obtained from the owners who brought their animals to the Veterinary Hospitals during the study period. A face to face owner's interview was performed to record the information using a separate questionnaire. The questionnaire included the following information; preliminary knowledge about ND, time required to show the clinical signs, knowledge about ND vaccine and its source etc. Suspected ND affected poultry was diagnosed by according to following clinical history and signs taken from the owner's interview and sometimes (not always) supported with post mortem examination findings. Drowsiness, greenish to whitish diarrhoea, torticollis, decline in egg production, respiratory distress was found as the main signs of ND. The age of the species was determined by asking from the owners and breed was assessed according to phenotypic characteristics.

\section{Prevalence calculation}

Data obtained were entered into Microsoft Excel 2007 and exported to STATA-13 (STATA Corporation, 4905, Lakeway River, College Station, Texas 77845, USA) for statistical analysis. Descriptive analysis was performed. Fisher's exact test was applied 
to access the difference between the proportions of ND and nonNewcastle Disease cases in relation to different categories of variable. The results were expressed in frequency, number and percentage each category of variable and $p$ value. The level of significance was set at $p \leq 0.05$ (Figure 1-6).

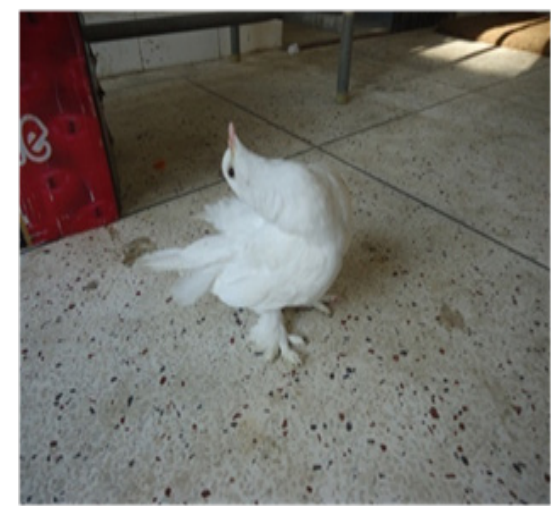

Figure I Bending of neck.

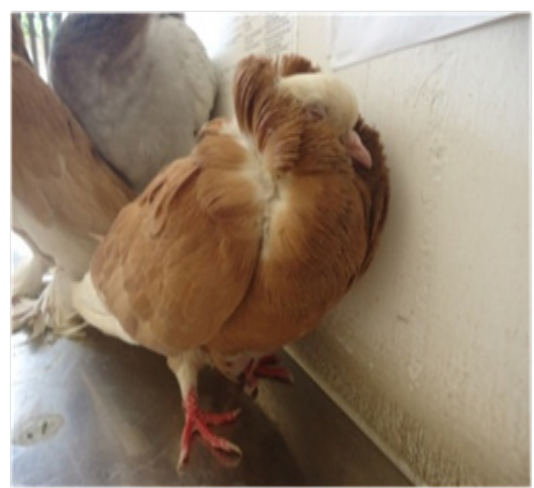

Figure 2 Weakness and drowsiness.

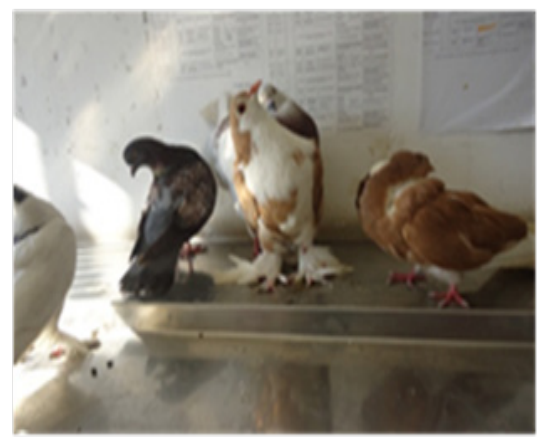

Figure 3 Digestive disorder.

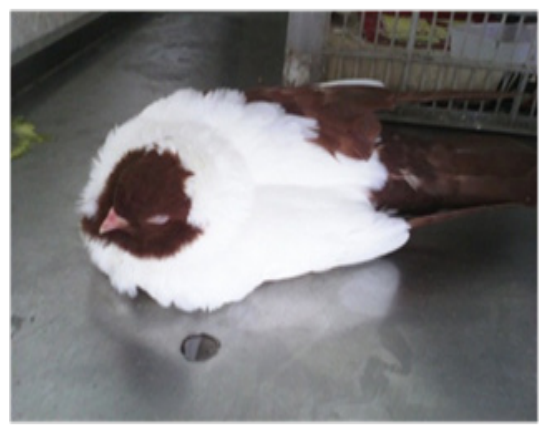

Figure 4 Respiratory distress.

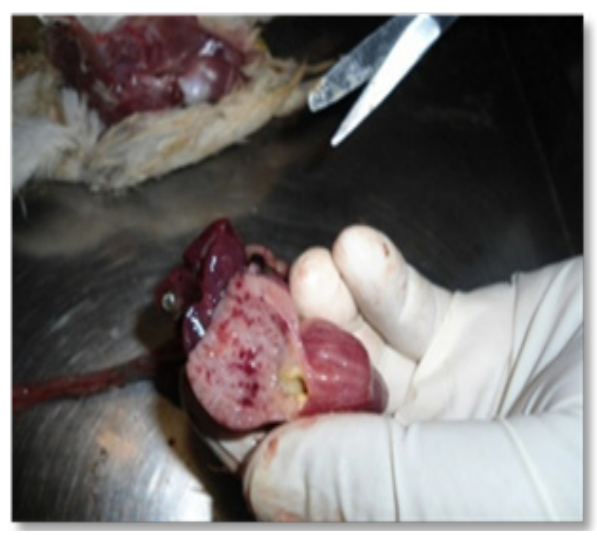

Figure 5 Hemmorhage in tip of gland in proventriculus.

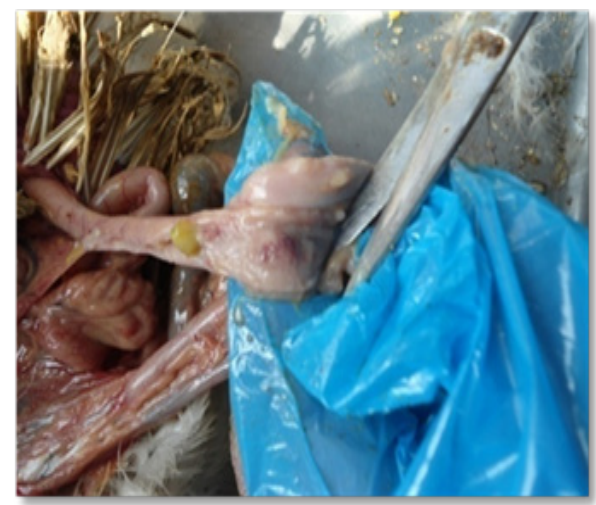

Figure 6 Button ulcer in intestinal mucosa.

\section{Results}

\section{The proportionate prevalence of new castle disease in chicken, pigeon and duck in studied area}

The estimated proportionate prevalence of ND in pigeon, chicken and duck were $56 \%, 45 \%$ and $43.75 \%$ in UVH; $58.9 \%, 32 \%$ and $17.1 \%$ in SAQTVH and $32.5 \%, 36.4 \%$ and $20 \%$ in TANUVAS, respectively (Table 1). The ND was higher in pigeon (56\%) than in chicken (45\%) in UVH but the differences is not statistically significant ( $p>0.05)$. The proportionate prevalence of ND was statistically higher $(\mathrm{p}<0.05)$ in pigeon $(58.9 \%)$ than in chicken $(32 \%)$ in SAQTVH placements. In TANUVAS the proportionate prevalence of ND was slightly higher in chicken $(36.4 \%)$ than in pigeon $(32.5 \%)(p<0.05)$. Comparison among three species at TANUVAS, the proportionate prevalence of ND was higher in chicken (36.4\%) than either in pigeon $(32.5 \%)$ or duck $(20 \%)$.

\section{Distribution of proportionate prevalence of ND in sex of birds}

In UVH, the proportionate prevalence of ND in male and female was respectively, $50 \%$ and $58.3 \%$ in pigeon; $38.5 \%$ and $48.1 \%$ in chicken; $40 \%$ and $45.5 \%$ in duck. In SAQTVH, the proportionate prevalence of ND in male and female was respectively, $53.8 \%$ and $60.9 \%$ in pigeon; $23.1 \%$ and $36 \%$ in chicken; $14.2 \%$ and $19 \%$ in duck. In TANUVAS, the proportionate prevalence of ND in male and female was $31.8 \%$ and $32.8 \%$ respectively, in pigeon; $23.7 \%$ and $43.2 \%$ respectively, in chicken; $16.6 \%$ and $16.6 \%$ respectively in duck (Table 2). 
Table I Frequency of newcastle disease in chicken, pigeon and duck in studied area

\begin{tabular}{|c|c|c|c|c|c|c|c|c|c|}
\hline \multirow{3}{*}{ Species } & \multicolumn{3}{|c|}{ UVH } & \multicolumn{3}{|c|}{ SAQTVH } & \multicolumn{3}{|c|}{ TANUVAS } \\
\hline & \multicolumn{3}{|c|}{ Newcastle disease } & \multicolumn{3}{|c|}{ Newcastle disease } & \multicolumn{3}{|c|}{ Newcastle disease } \\
\hline & $\mathbf{N}$ & Yes(\%) & No(\%) & $\mathbf{N}$ & Yes(\%) & No(\%) & $\mathbf{N}$ & Yes(\%) & No(\%) \\
\hline Pigeon & 50 & $28(56 \%)$ & $22(44 \%)$ & 90 & $53(58.9 \%)$ & $37(41.1 \%)$ & 80 & $26(32.5 \%)$ & $54(67.5 \%)$ \\
\hline Chicken & 40 & I8(45\%) & $22(55 \%)$ & 125 & $40(32 \%)$ & $85(68 \%)$ & 170 & $62(36.4 \%)$ & $108(63.5 \%)$ \\
\hline Duck & 16 & $7(43.8 \%)$ & $8(50 \%)$ & 35 & $6(17.1 \%)$ & $29(82.8 \%)$ & 25 & $5(20 \%)$ & $20(80 \%)$ \\
\hline$P$ value & & 0.504 & & 0.0001 & & & 0.097 & & \\
\hline
\end{tabular}

UVH, upazilla veterinary hospital; SAQTVH, shahedul alam quaderi teaching veterinary hospital;TANUVAS, tamilnadu veterinary and animal sciences university; $\mathrm{N}$, total number

Table 2 Distribution of prevalence of in sex of birds

\begin{tabular}{|c|c|c|c|c|c|c|c|c|c|c|c|c|}
\hline \multirow{2}{*}{ Area } & \multirow{2}{*}{ Age } & \multicolumn{3}{|c|}{ Pigeon } & \multicolumn{3}{|c|}{ Chicken } & \multicolumn{3}{|c|}{ Duck } & \multirow{2}{*}{$\chi^{2}$-value } & \multirow{2}{*}{ P-value } \\
\hline & & $\mathbf{N}$ & $+(\%)$ & - & $\mathbf{N}$ & $+(\%)$ & - & $\mathbf{N}$ & $+(\%)$ & - & & \\
\hline \multirow{3}{*}{ UVH } & $<3$ months & 27 & 16(59.3) & II & 24 & I4(58.3) & 10 & 7 & $4(57)$ & 3 & \multirow{3}{*}{4.2} & \multirow{3}{*}{0.12} \\
\hline & 3-4months & 13 & $8(6 I .5)$ & 5 & 8 & $I(I 2.5)$ & 7 & 4 & $2(50)$ & 2 & & \\
\hline & $>4$ months & 10 & $4(40)$ & 6 & 8 & $3(37.5)$ & 5 & 5 & $\mathrm{I}(20)$ & 4 & & \\
\hline \multirow{3}{*}{ SAQTVH } & $<3$ months & 25 & $15(60)$ & 10 & 57 & $22(38.6)$ & 35 & 8 & $0(0)$ & 8 & \multirow{3}{*}{2.66} & \multirow{3}{*}{0.26} \\
\hline & 3-4months & 25 & $13(52)$ & 12 & 38 & $8(21)$ & 30 & 8 & $2(25)$ & 6 & & \\
\hline & $>4$ months & 40 & $26(65)$ & 14 & 30 & $10(33.3)$ & 20 & 19 & $4(2 I . I)$ & 15 & & \\
\hline \multirow{3}{*}{ TANUVAS } & $<3$ months & 26 & $8(30.8)$ & 18 & 120 & $45(37.5)$ & 75 & 8 & $2(25)$ & 6 & \multirow{3}{*}{3.37} & \multirow{3}{*}{0.19} \\
\hline & 3-4months & 29 & $9(31)$ & 20 & 22 & $2(9.1)$ & 20 & 9 & $3(33.3)$ & 6 & & \\
\hline & $>4$ months & 25 & $9(36)$ & 16 & 28 & I5(53.6) & 13 & 8 & $0(0)$ & 8 & & \\
\hline
\end{tabular}

Distribution of proportionate prevalence of new castle disease in age of birds

The frequencies of ND in young birds were frequently higher than older birds. In this current study the findings showed that frequency of ND was $0-60 \%$ in below 3months of age, 9.09-61.53\% in between 3 to 4 months of age, $0-65 \%$ in above 4 months of age. This outcome matches with a study in Nigeria indicated that in backyard management systems birds around 16 to 24 weeks of age were at the highest risk of Newcastle disease virus infection (Table 3). ${ }^{19}$

\section{Distribution of proportionate prevalence of new cast-} le disease by clinical signs

Different body systems were found affected with ND and they were digestive system, respiratory system, nervous system and reproductive system. Digestive signs $(50 \%)$, digestive and nervous signs $(9.2 \%)$, digestive and reproductive signs (13.3\%), digestive and respiratory signs $(19.2 \%)$, nervous signs $(8.3 \%)$ were found in 120 chicken. Digestive signs $(27.8 \%)$, digestive and nervous signs (33.3\%), digestive and reproductive signs $(11.1 \%)$, digestive and respiratory signs $(11.1 \%)$, nervous signs $(16.7 \%)$ respectively also noted in 18 ND affected ducks. Digestive signs (35.5\%), digestive and nervous signs $(16.8 \%)$, digestive and reproductive signs $(0.9 \%)$, digestive and respiratory signs $(13.1 \%)$, nervous signs $(33.6 \%)$ were noticed in ND affected 107 pigeons (Table 4).

\section{Distribution of proportionate prevalence of new cast- le disease in seasons}

In $\mathrm{UVH}$, the proportionate prevalence of ND was respectively, $15.1 \%, 13.2 \%, 28.3 \%$, and $43.4 \%$ in autumn, rainy, summer, and winter season. In SAQTVH, the proportionate prevalence of ND was respectively, $14.1 \%, 12.1 \%, 50.5 \%$, and $23.2 \%$ in autumn, rainy, summer, and winter season. In TANUVAS, the proportionate prevalence of ND was respectively, $22.6 \%, 6.4 \%, 63.4 \%$, and $7.5 \%$ in autumn, rainy, summer, and winter season. However the prevalence of occurrence of ND was highest in summer season (Table 5) (Figure 7).

\section{Distribution of proportionate prevalence of new cast-} le disease in vaccination status

$65.8 \%$ chicken, $19.6 \%$ pigeon and $23.5 \%$ duck were found vaccinated across the study period (Figure 8 ). 
Table 3 Frequency distribution of prevalence of newcastle disease in age of birds

\begin{tabular}{lllllll}
\hline Species & DS(\%) & DNS(\%) & DRpS(\%) & DRsS(\%) & NS(\%) & Total(\%) \\
\hline Chicken & $60(50)$ & $11(9.2)$ & $16(13.3)$ & $23(19.2)$ & $10(8.3)$ & 120 \\
Duck & $5(27.8)$ & $6(33.3)$ & $2(11.1)$ & $2(11.1)$ & $3(16.7)$ & 18 \\
Pigeon & $38(35.5)$ & $18(16.8)$ & $1(0.9)$ & $14(13.1)$ & $36(33.6)$ & 107 \\
Total & $103(42)$ & $35(14.3)$ & $19(7.8)$ & $39(15.9)$ & $49(20)$ & 245
\end{tabular}

DS, digestive system; DNS, digestive and nervous system; DRpS, digestive and reproductive system; DRS, digestive and respiratory system; NS, nervous system

Table 4 Distribution of prevalence of newcastle disease by clinical signs

\begin{tabular}{llllll}
\hline Placements & Autumn(\%) & Rainy(\%) & Summer(\%) & Winter(\%) & Total(\%) \\
\hline UVH & $8(I 5 . I)$ & $7(13.2)$ & $15(28.3)$ & $23(43.4)$ & 53 \\
SAQTVH & $14(\mid 4.1)$ & $12(12.1)$ & $50(50.5)$ & $23(23.2)$ & 99 \\
TANUVAS & $2 I(22.6)$ & $6(6.4)$ & $59(63.4)$ & $7(7.5)$ & 93 \\
Total & $43(17.6)$ & $25(10.2)$ & $124(50.6)$ & $53(21.6)$ & 245 \\
\hline
\end{tabular}

Table 5 Seasonal Distribution of prevalence of newcastle disease in seasons

\begin{tabular}{llllllllll}
\hline \multirow{2}{*}{ Placements } & \multicolumn{2}{l}{ Chicken } & \multicolumn{3}{l}{ Pigeon } & \multicolumn{3}{c}{ Duck } \\
\cline { 2 - 10 } & N & Yes(\%) & No & N & Yes(\%) & No & N & Yes(\%) & No \\
\hline UVH & 18 & II (6I.I) & 7 & 28 & $3(10.7)$ & 25 & 6 & I (I6.7) & 5 \\
SAQTVH & 40 & $20(50)$ & 20 & 53 & $13(24.5)$ & 40 & 6 & I(I6.7) & 5 \\
TANUVAS & 62 & $48(77.4)$ & 14 & 26 & $5(19.2)$ & 21 & 5 & $2(40)$ & 3 \\
Total & 120 & $79(65.8)$ & $4 I$ & 107 & $21(19.6)$ & 86 & 17 & $4(23.5)$ & 13 \\
\hline
\end{tabular}

UVH, upazilla veterinary hospital; SAQTVH, shahedul alam quaderi teaching veterinary hospital;TANUVAS, tamilnadu veterinary and animal sciences university; $\mathrm{N}$, total number

Table 6 Frequency Distribution of prevalence of newcastle disease in vaccination status

\begin{tabular}{|c|c|c|c|c|c|c|c|c|c|c|c|c|}
\hline \multirow{2}{*}{ Area } & \multirow{2}{*}{ Age } & \multicolumn{3}{|c|}{ Pigeon } & \multicolumn{3}{|c|}{ Chicken } & \multicolumn{3}{|c|}{ Duck } & \multirow{2}{*}{$\chi^{2}$-value } & \multirow{2}{*}{ P-value } \\
\hline & & $\mathbf{N}$ & $+(\%)$ & - & $\mathbf{N}$ & $+(\%)$ & - & $\mathbf{N}$ & $+(\%)$ & - & & \\
\hline \multirow{2}{*}{ UVH } & Male & 14 & $7(50)$ & 7 & 13 & $5(38.5)$ & 8 & 5 & $2(40)$ & 3 & \multirow{2}{*}{0.72} & \multirow{2}{*}{0.39} \\
\hline & Female & 36 & $2 \mid(58.3)$ & 15 & 27 & I3(48.I) & 14 & II & $5(45.5)$ & 6 & & \\
\hline \multirow{2}{*}{ SAQTVH } & Male & 26 & |4(53.8) & 12 & 39 & $9(23.1)$ & 30 & 14 & $2(14.2)$ & 12 & \multirow{2}{*}{3.06} & \multirow{2}{*}{0.08} \\
\hline & Female & 64 & $39(60.9)$ & 25 & 86 & $3 I(36)$ & 55 & 21 & $4(19)$ & 17 & & \\
\hline \multirow{2}{*}{ TANUVAS } & Male & 22 & $7(31.8)$ & 15 & 59 & |4(23.7) & 45 & 12 & $2(16.6)$ & 10 & \multirow{2}{*}{5.34} & \multirow{2}{*}{0.02} \\
\hline & Female & 58 & $19(32.8)$ & 39 & III & $48(43.2)$ & 63 & 18 & $3(16.6)$ & 15 & & \\
\hline
\end{tabular}

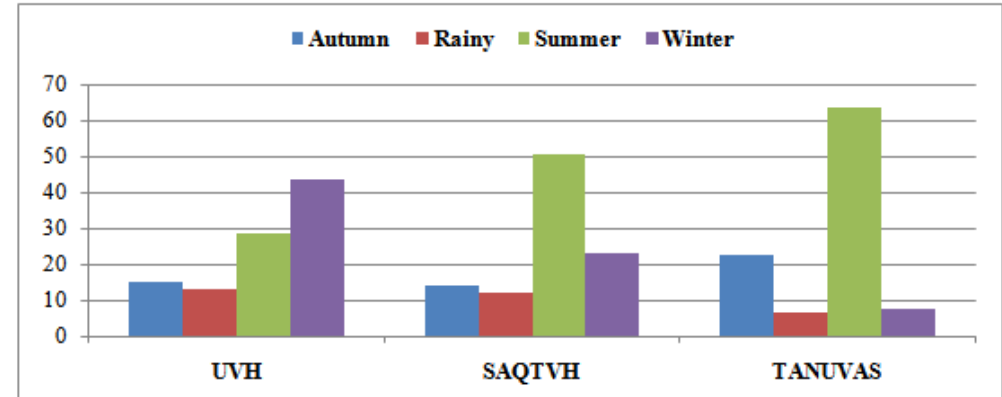

Figure 7 Distribution of proportionate prevalence of newcastle disease in vaccination status.

Citation: Munmun T, Islam KMF, Jalal S, et al. Investigation of proportionate prevalence of new castle disease in chicken, pigeon and duck at selected veterinary hospitals in Bangladesh and India.J Dairy Vet Anim Res. 2016;4(2):284-29I. DOI: I0.15406/jdvar.20I6.04.00II 8 
- Chicken $\square$ Pigeon $\square$ Duck

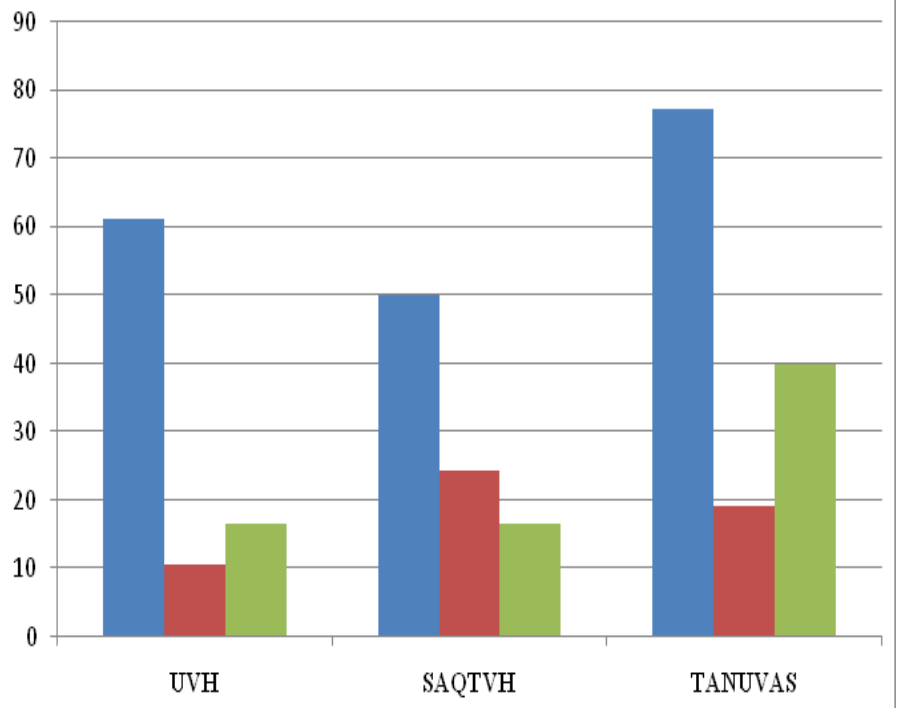

Figure 8 Frequency distribution of prevalence of newcastle disease in vaccination status.

\section{Discussion}

Newcastle disease is a threat for poultry industry which causes high mortality and morbidity. Newcastle Disease is said to occur in poultry population throughout the year in most of the country. ND virus infects wide variety of host but in this study ND was present for chicken, pigeon and duck. In my study the proportionate prevalence of ND was $32.5-58.88 \%$ in pigeon, $32-45 \%$ in chicken, $17.1-43.75 \%$ in duck which is matched with previous study. ${ }^{20}$ In Hathazari Upazilla Veterinary Hospital the frequency of ND was higher in pigeon, chicken than duck because of a large number of pigeon and chicken populations in this site. In TANUVAS, the frequency of ND is higher in chicken due to large population of chicken and also housing together of them may be another possible cause for the occurrence of ND. ${ }^{21}$

ND can occur in any of life but as the age of bird increases it gradually built strong immunity against this disease. Generally, young birds are more susceptible to ND. In this current study the findings showed that frequency of ND was $0-60 \%$ in below 3months of age, 9.09-61.53\% in between 3 to 4 months of age, $0-65 \%$ in above 4 months of age. This outcome matches with a study in Nigeria indicated that in backyard management systems birds around 16 to 24 weeks of age were at the highest risk of Newcastle disease virus infection. ${ }^{19}$

Both male and female were susceptible to Newcastle disease. But it was found that rate of prevalence of ND in female was a bit higher than male. Previous studied by Kutubuddin ${ }^{22}$ indicated that male birds were more affected by Newcastle disease virus than female birds. However, it does not matched with this current study as female have the higher viral load there than the male. The actual cause of this apparent sex related difference in carriage of the Newcastle disease virus is still not understood.

In this study ND was present for the whole year round but there was change on its prevalence in different season. Previous studies reported association of ND with change of seasons, some reported its high incidence in wet season. ${ }^{23}$ Cold weather has been associated with ND outbreaks in some countries. ${ }^{24}$ While in others its hot weather ${ }^{25}$ and others with cold and hot season. ${ }^{26}$ In this study showed that prevalence was highest in summer season (50.61\%). This result has similarity with Ratana sethakul ${ }^{27}$ who stated that in Thailand cases of ND occur throughout the year but the incidence peaks at the end of the dry season between February and April. The study finding has also agreement with this statement that the highest incidence of ND in rural poultry in Uganda is reported during hot and dry period of the year ${ }^{28,29}$ and in Nepal during the summer. ${ }^{30}$ Martin $^{31}$ in a review concluded that ND outbreaks are often associated with the change of the season, specifically at the start of the wet season, with cold and hot weather. This present study findings is also similar with this agreement because the prevalence of ND was very low in the rainy season $(10.20 \%)$ and in autumn (17.55\%) only when weather of Bangladesh remains in a moderate temperature as not too cold and also not very hot. But reviewing the information cited above it is appears that the incidence of ND is not associated with any particular season but rather with periods of climatic stress.

In this study, different body systems were mostly clinically affected with ND: digestive system (42.04\%), digestive and nervous system (14.28\%), digestive and reproductive system $(7.75 \%)$, digestive and respiratory system $(15.91 \%)$, nervous system $(20 \%)$ respectively. In viscerotropic velogenic form of the disease, the digestive system is affected the most, and in neurotropic velogenic form the nervous system is affected. In this study the prevalence of digestive system related clinical symptoms were somewhat greater than the nervous system, but the virus pathotypes involved in these symptoms could not be known.

In this study, unvaccinated birds were mostly affected with ND than vaccinated birds. But in this study, a little portion of vaccinated birds were affected by ND, may be due to vaccine failure or due to a wrong timing of vaccination or presence of others concurrent infections or due to stress condition. ND killed vaccine may increase the protective titre level of the flock immediately against ND when the flock was previously vaccinated with any short of ND vaccine. Ultimately it may reduce the mortality rate of the flock affected with ND.

Routine vaccination of all bird species may aid in prevention of outbreak of Newcastle Disease. This is the need for public enlightment, especially those engaged in poultry farming and individuals keeping pet or game birds on the economic importance of ND to the poultry industry. Birds of different species should be segregated while newly acquired birds should be quarantined.

\section{Limitations}

The study was conducted in a small scale, area and short time period which might not be the representative.

\section{Conclusion}

Newcastle Disease was higher in younger birds than older birds irrespective of species. The female birds were susceptible than in male birds. Newcastle Disease virus infects most of species especially chicken, pigeon, duck. Drowsiness, respiratory distress, torticollis, greenish diarrhoea, decline in egg production are the clinical symptoms of ND from the owners complaints. In this study, occurrence of ND is higher in summer than rainy and autumn irrespective of seasons. Routine vaccination should be maintained which may help in control strategies of ND. Therefore, updated information is essential to understand the epidemiology of different diseases in birds to design prevention and control strategies. 


\section{Acknowledgements}

None.

\section{Conflict of interest}

Author declares that there is no conflict of interest.

\section{References}

1. Kianizadeh, Ideris, Shahrabadi, et al. Biological and molecular characterization Newcastle disease virus isolated from Iran. Arch Razi Ins. 1999;50:1-9.

2. Alexander DJ. Newcastle disease, other Parmyxoviruses and Pneumovirus Infections. In: Saif YM, editor. Diseases of Poultry. Ames, USA: Iowa State press; 2003. p. 63-100.

3. Rima B Alexander, DJ Billeter, MA Collins, et al. Paramyxoviridae Virus taxonomy. 6th report of the International Committee on Taxonomy of Viruses. Vienna and New York: Springer-Verlag; 1995. p. 268-274.

4. Kaleta EF, Baldauf C. Newcastle disease in free living and pet birds. In: DJ Alexander, editor. Newcastle Disease. Boston, MA: Kluwer Academic Publishers; 1988. p. 197-246.

5. Alexander DJ. Newcastle disease and other avian paramyxoviruses. Rev Sci Tech Off Int Epiz. 2000;19(2):443-462.

6. Arnall L, IP Keymer. Bird Diseases. Baillere and Tindall, 8 Henrietta Street London; 1975:451-459.

7. Office International Epizooties Disease Information. OIE. 2000.

8. Al-Garib SO, Gielkens ALJ, Koch G. Review of Newcastle disease virus with particular references to immunity and vaccination. World's Poultry Science Journal. 2003;59(2):185-197.

9. Ballagi PA, Wehmann E. Identification and grouping of Newcastle disease virus strains by Restriction site analysis of a region from the $\mathrm{F}$ gene. Arch Virol. 1996;141(2):243-261.

10. Beard CW, Hanson RP. Newcastle disease. In: Hofstad MS, editor. Diseases of Poultry. 8th ed. Ames: Iowa State University Press; 1984. p. $452-470$

11. Spradbrow PB. Newcastle disease in Australia. Newcastle disease in poultry: a new feed pellet vaccine. The Australian Centre for international agricultural research. 1987. p. 40-43.

12. Tu TD, Phuc KV, Dinh NT, et al. Vietnam trials with a thermostable Newcastle disease vaccine (strain I2) in experimental and village chickens. Preventive Veterinary Medicine. 1998;34(2-3):205-214.

13. Mc Ferran JB, McCracken RM. Newcastle disease. In: Alexander DJ, editor. USA: Kluwer Academic Publisher; 1988. p. 161-183.

14. Alexnader DJ. Newcastle disease and other avian paramyxoviridae infections. In: Calnek BW, editor. Diseases of Poultry. 10th ed. Ames, USA: Iowa State University Press; 1997. p. 541-569.

15. Orajaka LJE, Adene DF, Anene BM, et al. Seroprevalence of Newcastle disease in local chickens from Southeast derived savannah zone of Nigeria. Revue Elevage Médecine Vétérinaire Pays Tropicaux. 1999;52(3-4):185-188.

16. Chowdhury SI, Chowdhury T, Sarker AJ, et al. The role of residual maternal antibody on immune response and selection of an optimum age for primary vaccination of chicks. Studies on Newcastle disease in Bangladesh. A research report. 1982;2(12-22).

17. Rahman MM, Bari ASM, Giusuddin M, et al. Evaluation of maternal and humoral immunity against Newcastle disease virus in chicken. International Journal of Poultry Science. 2002;1:161-163.
18. Allan WH, Lancaster JA, Toth B. Newcastle disease vaccines: their production and use. FAO animal production and health series, No. 10. Rome, Italy: FAO; 1978.

19. Ezeokoli CD, Umoh JU, Adesiyun AA, et al. Prevalence of Newcastle disease virus antibodies in local and exotic chicken under different management systems in Nigeria. Bulletin of Animal Health and Production in Africa. 1984;32:253

20. Asadullah M. Village chickens and Newcastle disease in Bangladesh. In: Spradbrow PB, editor. Newcastle Disease in Village Chickens, Control with Thermostable Oral Vaccines. Proceedings, International Workshop held in Kuala Lumpur, Malaysia, 6-10 October 1991. Canberra: Centre for International Agricultural Research (ACIAR); 1992. p. 161-162.

21. Ucan SU. Housing quails and chickens together is the possible cause of Newcastle disease spread: an overlooked measure taken to prevent the disease. E Turk J Vet Anim Sci. 2002;26:419-420.

22. Kutubuddin K. Pathological investigation on the causes of mortality of chickens in the BAU poultry farm M.Sc. Thesis. Department of Pathology. Mymensingh: Faculty of Veterinary Science Bangladesh Agricultural University; 1973.

23. Thitisak W, Janviriyasopak O, Morris RS, et al. A poultry health and productivity profile - diseases and control measures. In: Proceedings, International Seminaron Animal Health and Production Services for Village Livestock. Khon Kaen, Thailand; 1989. p. 409-415.

24. Dao TD, Pham C. National overviews; Vietnam In: Della-Porta AJ, editor. Veterinary viral diseases: their significance in south-east Asia and the western Pacific. Sydney, Australia: Academic press; 1985. p. 246-250.

25. Bell JG, Kane M, Le Jan C. An investigation of the disease status of village poultry in Mauritania. Preventive Veterinary Medicine. 1990;8(4):291-294.

26. Nyaga JM, Nyaga PN, Kariuki DP. Epidemiology of Newcastle disease in Kenya. Bulletin of Animal Health and Production in Africa. 1985;33:249-251.

27. Ratanasethakul C. Disease problems of importance in Thai village poultry. Proceedings, International Seminar on Animal Health and Production Services for Village Livestock. Khon Kaen, Thailand; 1989. p. 113-115.

28. George MM. Epidemiology of Newcastle disease in rural Uganda. In: Rweyemamu MM, editor. Newcastle Disease Vaccines for Rural Africa. Proceedings of a Workshop held at Pan African Veterinary Vaccine Centre (PANVAC). Debre Zeit, Addis Ababa, Ethiopia; 1991:75-76.

29. George MM. Epidemiology of Newcastle disease and the need to vaccinate local chickens in Uganda. In: Spradbrow PB, editor. Newcastle Disease in Village Chickens, Control with Thermostable Oral Vaccines. Canberra: Proceedings, International Workshop held in Kuala Lumpur, Malaysia, 6-10 October 1991, Centre for International Agricultural Research (ACIAR); 1992. p. 155-158.

30. Mishra U. Present status of poultry in Nepal. In: Spradbrow PB, editor Newcastle Disease in Village Chickens, Control with Thermostable Oral Vaccines. Proceedings, International Workshop held inKuala Lumpur, Malaysia, 6-10 October 1991, Canberra: Centre for International Agricultural Research (ACIAR); 1992. p. 163-166.

31. Martin PAJ. The epidemiology of Newcastle disease in village chickens In: Spradbrow PB, editor. Newcastle Disease in Village Chickens, Control with Thermostable Oral Vaccines. Proceedings, International Workshop held in Kuala Lumpur, Malaysia, 6-10 October 1991, Canberra: Centre for International Agricultural Research (ACIAR); 1992. p. 40-45. 
32. Bell JG, Ait belarbid, Amara A. A controlled vaccination trial for Newcastle disease under village conditions. Preventive Veterinary Medicine. 1990;9:295-300.
33. Chowdhury TIMR, Sarker AJ, Amin MM, et al. Studies on Newcastle Disease in Bangladesh. A Research Report 3. 1982. 